\title{
Peran BUMDes dalam Pengelolaan Sampah dengan Insinerator dan Komposter di Desa Sumbergondo, Kota Batu
}

Rafi Alfiansyah ${ }^{* 1}$

${ }^{1}$ Mahasiswa Program Studi Sosiologi, Fakultas Ilmu Sosial dan Ilmu Politik, Universitas Muhammadiyah Malang, Jalan Raya Tlogomas No. 246 Malang

\section{Kata Kunci:} peran BUMDes, pengelolaan sampah, insinerator, komposter

\begin{abstract}
Abstrak
Masalah sampah menjadi sebuah isu yang begitu penting, karena memberikan dampak terhadap lingkungan, sehingga perlu diperhatikan bagi seluruh elemen yaitu Pemerintah maupun rakyat. Desa Sumbergondo, Kota Batu pernah menghadapi persoalan serius akan sampah. Volume sampah yang diproduksi tidak sebanding dengan sarana dan prasarana dalam pengelolaan sampah, sehingga sampah dibuang secara sembarangan dan menumpuk pada satu tempat sehingga dapat menimbulkan dampak negatif bagi lingkungan, kesehatan dan kenyamanan. Namun BUMDes, sekitar tahun 2019 menciptakan alat peengelolaan sampah yaitu insinerator dan komposter dengan penggunaan Dana Desa. Tujuan dilaksanakan penelitian ini (1) menjelaskan peran BUMDes terkait manajemen sampah di Desa Sumbergondo (2) memahami serta melihat akibat yang dirasakan warga Desa Sumbergondo sesudah ditemukan alat insinerator dan komposter dalam pengelolaan sampah di Desa Sumbergondo. Penelitian dilakukan dengan menggunakan pendekatan kualitatif dan jenis penelitian deskriptif. Teknik untuk pengumpulan datanya menggunakan observasi, wawancara dan dokumentasi. Hasil temuan penelitian berupa BUMDes memiliki peran penting dalam suksesnya pengelolaan sampah di Desa Sumbergondo, melalui program bank sampah dan alat insinerator dan komposter yang diciptakan BUMDes bisa mengatasi permasalahan sampah di desanya. Abstract
The problem of waste is an issue that is so important, because it has an
impact on the environment, so it needs to be paid attention to all elements,
namely the Government and the people. Sumbergondo Village, Batu City
once faced a serious problem with waste. The volume of waste produced is
not proportional to the facilities and infrastructure in waste management,
so waste is disposed of carelessly and piles up in one place so that it can
have a negative impact on the environment, health and comfort. However,
BUMDes, around 2019 created a waste management tool, namely an
incinerator and composter using the Village Fund. The purpose of this
research is (1) explaining the role of BUMDes related to waste
management in Sumbergondo Village (2) understanding and seeing the
effects felt by residents of Sumbergondo Village after finding incenerator
\end{abstract}

Keywords:
role of BUMDes, waste
management,
incenerator, composter

*e-mail : rafialfiansyah.28.02@gmail.com 
and composter tools in waste management in Sumbergondo Village. The research was conducted using a qualitative approach and descriptive research type. Techniques for collecting data using observation, interviews and documentation. The results of the research findings in the form of BUMDes have an important role in the success of waste management in Sumbergondo Village, through the Waste Bank program and the incinerator and composter tools created by BUMDes that can overcome waste problems in their village.

\section{PENDAHULUAN}

Sampah menjadi permasalahan yang begitu penting, ketika populasi manusia dan hewan mengalami peningkatan yang dapat menghasilkan limbah, selain itu dampak dari aktivitas proses produksi \& konsumsi, juga berakibat pada kenaikan timbunan sampah. Bersumber pada hasil penelitian Mulasari (2012) di dalam Jurnal Kesehatan Lingkungan karya Muchammad Zamzami Elamin, dkk. "Permasalahan sampah meliputi 3 bagian yaitu pada bagian hilir, proses dan hulu. Pada bagian hilir, pembuangan sampah yang terus meningkat. Pada bagian proses, keterbatasaan sumber daya baik dari masyarakat maupun pemerintah. Pada bagian hulu, berupa kurang optimalnya sistem yang diterapkan pada pemrosesan akhir" (Elamin et al., 2018).

Tumpukan sampah pada tempat tertentu turut mempengaruhi tingginya biaya. "Jika ditilik dari perspektif lingkungan, sampah merupakan materi 'mahal' karena dapat menimbulkan dampak lingkungan pada tingkat lokal, regional maupun global. Dari sudut pandang ekonomi, sampah merupakan nilai benda yang telah hilang, yang memiliki efek negatif terhadap umat manusia (bisa berupa gangguan ataupun bau busuk) dan dibutuhkan biaya yang tidak sedikit (untuk pengolahan maupun dalam penimbunannya dalam jangka panjang). Sampah juga merupakan masalah bagi generasi mendatang, karena adanya efek tunda dan biaya jangka panjang" (Arief, 2013).

Kurangnya perhatian masyarakat akan pentingnya dalam hal menjaga kelestarian lingkungan hidup menimbulkan dampak negatif yaitu perilaku membuang sampah secara sembarangan. Indonesia selalu mengalami kenaikan sampah per-harinya. Pada tahun 2019 jumlah sampah yang ada di Indonesia sebanyak 66-67 juta ton, kemudian pada tahun 2020 naik menjadi 67,8 juta ton.

Perihal tersebut menunjukkan bahwa

kurang efektif dalam hal tata kelola pemukiman dan tingginya laju peningkatan jumlah penduduk turut menjadi faktor meningkatnya sampah. Selain itu sarana dan prasarana yang digunakan dalam manajemen sampah serta pengetahuan masyarakat ketika menjaga kebersihan dan kelestarian lingkungan hidup juga menjadi indikator dalam mengelola sampah.

Maka dari itu sangat diperlukan bentuk kerja sama antara Pemerintah dengan rakyat atau masyarakat dalam mengelola sampah. Instansi Pemerintah dalam "pengelolaan sampah memiliki peran sebagai regulator/pembuat kebijakan serta sebagai penyedia layanan (service provider). Sebagai regulator pemerintah menetapkan kebijakan dan strategi dalam pengelolaan sampah. Sedangkan sebagai penyedia pelayanan adalah sebuah bentuk upaya pemerintah dalam memfasilitasi, mengembangkan dan melaksanakan pengurangan, penanganan dan pemanfaatan sampah" (Ariyanto \& Wibowo, 2020).

Pada sisi lainya partisipasi masyarakat juga dibutuhkan dalam mengelola sampah, dalam partisipasi pemikiran ini. "Masyarakat menyalurkan ide pengelolaan sampah tidak hanya dalam tahap perencanaan saja melainkan juga tahap pelaksanaan dan evaluasi program. Partisipasi tenaga dilihat dari masyarakat yang ikut serta dilapangan untuk membantu mulai dari mengumpulkan, mengambil sampah hingga mengelola sampah. Selanjutnya partisipasi keahlian atau ketrampilan dilihat dari bentuk usaha guna untuk mendorong aneka ragam usaha yang dilakukan oleh masyarakat" (Sulistiyorini, Darwis, \& Gutama, 2015).

Rakyat atau masyarakat tidak hanya ikut berpartisipasi dalam pengelolaan, melainkan harus ada tindak lanjut berupa inovasi dan temuan baru dalam pengelolaan sampah, seperti di Desa Sumbergondo, Badan Usaha Milik Desa berinovasi dalam pengelolaan sampah di desanya.

Desa Sumbergondo, Kecamatan Bumiaji, Kota Batu sempat mengalami 
persoalan serius akan sampah. Kapasitas sampah yang dihasilkan tidak setara dengan sarana dan prasarana yang digunakan. Banyaknya industri dan UKM yang ada, serta petani sayur dan buah-buahan membuat volume sampah di Desa Sumbergondo cukup tinggi. Volume presentase sampah terbesar berasal dari limbah sayuran dan buah-buahan. Masyarakat lebih suka membuang sampah di sungai, karena dirasa tidak ada solusi untuk pengelolaan sampah. TPA dan dua kontainer yang digunakan tidak bisa menampung banyaknya volume sampah yang ada. Selain itu sampah menumpuk dan berjejeran di pingir jalan sepanjang 50-100 meter yang ada di Desa Sumbergondo, sehingga menimbulkan dampak negatif bagi lingkungan, kesehatan serta kenyamanan. Namun pada Januari 2019 BUMDes Sumbergondo yang diberi nama Rejeki Barokah menciptakan sebuah alat pembakar sampah yang diberi nama insinerator dan komposter dengan menggunakan pembiayaan dari dana desa.

Setelah alat ditemukan terdapat beberapa aspek yang sekirannya harus di perhatikan. Merujuk pada penelitian Amurwaraharja (2003), dalam Jurnal Teknik Lingkungan yang ditulis Risqi Mahyudi "ada empat aspek yang perlu dipertimbangkan yaitu aspek sosial, ekonomi, lingkungan, dan teknis" (Mahyudin, 2017). "Kriteria dari aspek sosial diantaranya penyerapan tenaga kerja, menumbuhkan lapangan usaha pada sektor formal dan informal, penguatan peran serta masyarakat. Aspek ekonomi dapat dijabarkan menjadi tiga kriteria, yaitu investasi rendah, biaya operasional rendah, menghasilkan Pendapatan Asli Daerah (PAD) yang tinggi. Aspek lingkungan yaitu meminimalisir pencemaran air, bau dan estetika lingkungan"(Mahyudin, 2017).

Penelitian ini memiliki beberapa tujuan diantaranya menjelaskan terkait peran Badan Usaha Milik Desa dalam memanajemen sampah di Desa Sumbergondo serta memahami sekaligus melihat dampak yang dirasakan warga Desa Sumbergondo sesudah ditemukan alat insinerator dan komposter dalam pengelolaan sampah di Desa Sumbergondo.

\section{METODE PENELITIAN}

Pada penelitian ini memakai pendekatan kualitatif. Terkait jenis penelitian yang digunakan yaitu deskriptif, karena peneliti ingin mendeskripsikan dan menjelaskan sumber data yang diperoleh melalui informan dalam wujud kalimat yang real dan sesuai hasil temuan lapangan. Terdapat dua jenis data dalam penelitian ini yaitu data primer dan sekunder. Sumber data primer diperoleh melalui pengamatan lokasi, wawancara dan dokumentasi di lapangan, sedangkan sumber data sekunder diperoleh melalui studi kepustakaan. Teknik analisis data dilakukan dengan cara mereduksi data atau memilah data yang ditemukan di lapangan, kemudian penyajian data dan penarikan suatu kesimpulan.

\section{Lokasi Penelitian}

Desa Sumbergondo terletak di Kecamatan Bumiaji, Kota Batu, Provinsi Jawa Timur. Letak Desa Sumbergondo berada di sebelah utara Kota Batu, dengan luas $\pm 573 \mathrm{Ha}$. Terdapat tiga Dusun di Desa Sumbergondo yaitu Dusun Sengonan, Dusun Tegalsari,dan Dusun Segundu. Jumlah RT dan RW di Desa Sumbergondo yaitu terdapat 17 RT dan 3 RW. Mayoritas Penduduk Desa Sumbergondo bermata pencaharian sebagai petani maupun buruh sayur mayur dan buah. Jarak yang ditempuh dari kantor Kecamatan Bumiaji ke Desa Sumbergondo adalah $1,5 \mathrm{~km}$ atau 5 menit dengan jarak tempuh perjalanan menggunakan kendaraan bermotor/mobil, sedangkan jarak tempuh dari pusat Kota Batu ke Desa Sumbergondo adalah $6 \mathrm{~km}$ atau 20 menit.

\section{HASIL DAN PEMBAHASAN}

\section{Peran BUMDes Rejeki Barokah dalam Pengelolaan Sampah di Desa Sumbergondo, Kota Batu}

Peran menurut Soerjono Soekanto (2002) adalah "aspek dinamis yang berupa tindakan atau perilaku yang dilaksanakan oleh seseorang yang menempati atau memangku suatu posisi dan melaksanakan hak-hak dan kewajiban sesuaian dengan kedudukannya" (Soerjono Soekanto, 2002: 242).

BUMDes menurut Anom Surya Putra (2015) "merupakan salah satu bentuk kegiatan dalam hal peningkatan ekonomi desa yang dilaksanakan secara mandiri dan sukarelawan dengan cara memobilisasi unit-unit usaha mikro yang penting bagi usaha kolektif di desa" (Putra, 2015).

Menurut Purnomo (2004) adapun tujuan pembentukan Badan Usaha Milik Desa 
antara lain: "meningkatkan peranan masyarakat desa dalam mengelola sumber-sumber pendapatan lain yang sah, menumbuh kembangkan kegiatan ekonomi masyarakat desa, dalam unit-unit usaha desa, menumbuh kembangkan usaha sektor informal untuk dapat menyerap tenaga kerja masyarakat di desa, dan meningkatkan kreatifitas berwirausaha desa dan masyarakat desa yang berpenghasilan" (Purnomo, 2004: 17).

Menurut Sejati (2009) pengelolaan sampah adalah "semua kegiatan yang dilakukan untuk menangani sampah sejak ditimbulkan sampai dengan pembuangan akhir" (Sejati, 2009).

BUMDes Rejeki Barokah Desa Sumbergondo adalah salah satu BUMDes kreatif dan inovatif di Kota Batu. BUMDes Rejeki Barokah ini dikenal oleh masyarakat karena program pengelolaan sampah. Dengan program yang dibuat dan dilaksanakan, BUMDes Rejeki Barokah dapat mengelola sampah menjadi barang yang lebih bernilai dan bisa dimanfaatkan. BUMDes Rejeki Barokah memiliki peranan yang sangat penting dalam merancang dan menciptakan alat untuk mengelola sampah secara mandiri dengan menggunakan bantuan dana desa. Alat yang diciptakan antara lain insinerator dan komposter. Alat yang diciptakan memiliki fungsi tersendiri dalam mengelola jenis sampah yang ada.

Implementasi Teori Perubahan Sosial Selo Soemardjan

Pada penelitian ini yang menjadi tolak ukur yaitu teori perubahan sosial dari tokoh sosiolog Indonesia yaitu Selo Soemardjan. Menurut Selo Soemarjan (1986), perubahan sosial adalah "perubahan yang terjadi pada lembaga kemasyarakatan di dalam suatu masyarakat yang mempengaruhi sistem sosial, termasuk didalamnya nilai-nilai, sikap-sikap dan pola perilaku diantara kelompok dalam masyarakat" (Selo Soemardjan, 1986: 303).

Maka dari itu penulis mengunakan teori perubahan sosial, karena terdapat suatu perubahan sosial yang dilakukan oleh BUMDes dalam mempengaruhi sistem sosial terkait pengelolaan sampah. BUMDes melakukan sebuah perubahan terkait nilai, sikap dan pola perilaku dalam mengelola sampah di desanya dengan membuat dan merancang alat pengelola sampah, kemudian merealisasikan program terhadap warga.

\section{Jenis dan Sumber Sampah}

Dalam Undang- Undang No.18 Tahun 2008 tentang Pengelolaan Sampah, jenis dan sumber sampah yang diatur adalah:

1. Sampah rumah tangga adalah sampah yang berasal dari kegiatan sehari-hari dan bersumber dari rumah atau tempat tinggal, yang memiliki bentuk padat, semisal botol, plastik, kertas, dll.

2. Sampah organik atau basah yaitu jenis sampah yang dihasilkan dari proses kegiatan makhluk hidup berupa daun, sisa dari sayuran dan buah-buahan dan banyak muncul dari kegiatan pertanian dan pedagang sayur dan buah.

3. Sampah spesifik yaitu sampah sejenis rumah tangga yang di dalamnya terdapat bahan berbahaya dan beracun (B3), contoh baterai, hair spray, pembersih kaca dan oven, dll. Sampah ini mengandung zat kimia sehingga perlu penanganan khusus, karena jika berkontak langsung dengan lingkungan maka dapat merusak lingkungan.

Jenis Sampah di Desa Sumbergondo

1. Sampah rumah tangga yang tidak bisa diolah kembali

2. Sampah organik yang bisa dijadikan untuk pupuk daun dengan cara diolah ke dalam komposter

3. Sampah rumah tangga yang memiliki nilai ekonomi kemudian dikelola ke dalam Bank Sampah. Seperti jenis sampah kertas, plastik, botol dan bisa digunakkan untuk kegiatan warga dan menambah ekonomi.

\section{Teknik Pengangkutan Sampah}

BUMDes secara teknis bertanggung jawab dalam pengangkutan sampah, serta terdapat tong sampah berwarna hijau yang digunakan BUMDes untuk mengangkut sampah. Pengangkutan sampah dilakukan selama 1 minggu $2 x$ untuk dibawa kedalam insinerator, komposter dan bank sampah. 


\section{Teknik Pengelolaan Sampah dengan Insinerator}

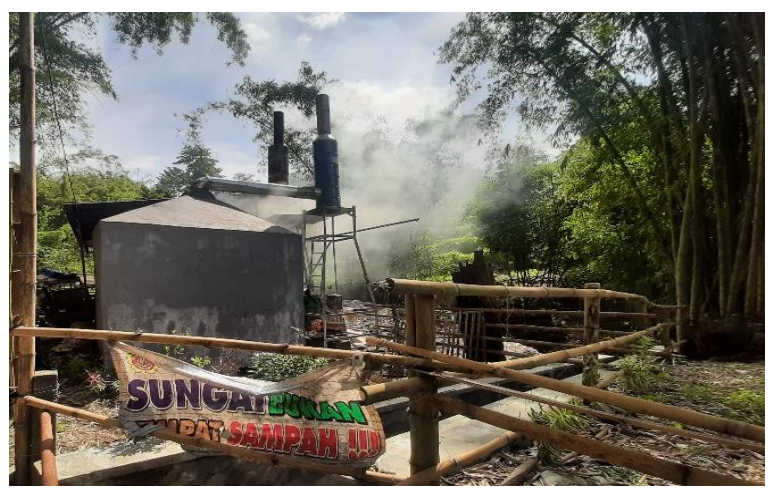

Sumber: Dokumentasi pribadi penulis (2020)

Gambar 1. Alat Insinerator.

Menurut Dian Purwitasari, dkk (2020) "insinerator merupakan teknologi alternatif yang menarik untuk mengolah sampah domestik melalui proses pembakaran karena memiliki beberapa keuntungan. Salah satunya yaitu insinerator mampu mengurangi volume sampah yang terbakar sampai $80-95 \%$ sehingga dapat menjaga ketersediaan landfill" (Dewanti, Ma'rufatin, Oktivia, \& Pratama, 2020).

Alat ini diciptakan pada bulan Januari 2019 oleh Karang Taruna dan BUMDes Desa Sumbergondo. Pembuatan alat insinerator menghabiskan biaya Rp. 60.000 .000 dengan menggunakan dana desa. Terdapat tiga alat insinerator yang ada di Desa Sumbergondo. Alat insinerator dikhususkan untuk mengelola sampah rumah tangga yang tidak bisa daur ulang atau dijadikan uang, dengan cara dibakar.

Satu alat insinerator dapat menampung sampah dengan jumlah kapasitas 600-800 kwintal. Secara sederhana dapat digunakan untuk 600 sampai 800 KK (Kepala Keluarga), 800 kepala keluarga terdiri sebanyak 4200 jiwa. Lokasi insinerator sengaja diletakkan di tengah kebun bambu supaya mengurangi kepulan asap yang ditimbulkan.

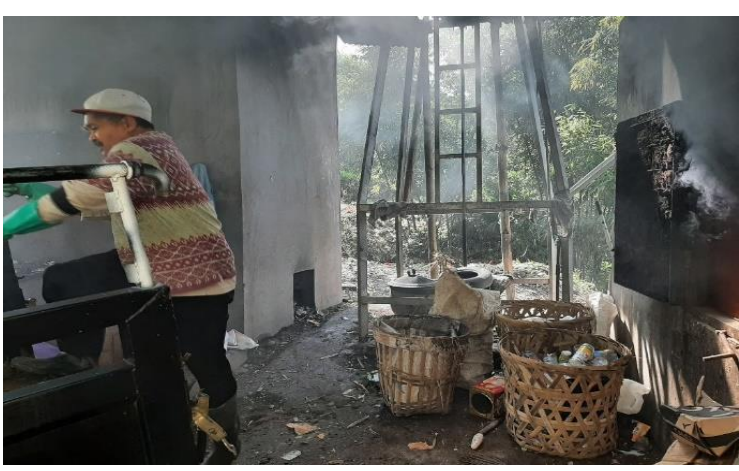

Sumber: Dokumentasi pribadi penulis (2020)

Gambar 2. Proses Pembakaran Sampah Rumah tangga.

Teknis pembakaran sampah rumah tangga melalui insinerator yaitu: memasukkan sampah ke dalam kotak insinerator, sampah dibakar dan menyalakan cerobong filter yang berada di atas bangunan insinerator, asap dari pembakaran di kasih filter dengan cara di semprot menggunakan pipa air, sehingga asapnya bisa berkurang, tidak berbau dan warnanya jadi cerah serta teknologi bersifat ramah lingkungan, kemudian abu dari hasil pembakaran sampah bisa dimanfaatkan untuk dijadikan pupuk kering.

Proses pembakaran sampah rumah tangga dengan insinerator yang tidak sempurna dapat berdampak terbentuknya dioksin. "Dioksin merupakan senyawa yang mampu mengacaukan sistem hormon, yaitu dengan cara bergabung dengan kaseptor hormon, sehingga mengubah fungsi dan mekanisme genetis dari sel, dan mengakibatkan pengaruh yang sangat luas, yaitu kanker, menurunkan daya tahan tubuh, mengacaukan sistem saraf, keguguran kandungan, dan dapat mengakibatkan cacat kelahiran. Umumnya dioksin dihasilkan dari pembakaran sampah yang merupakan hasil samping produk pestisida, pembakaran dari proses produksi baja atau proses kimia suatu produk yang menggunakan chlor sebagai pemutih seperti kertas, plastik, bahan Tshirt dan sebagainya" (Kodrat, 2013).Selain itu berdasarkan hasil penelitian yang telah dilakukan oleh Sumingkrat (2002) "Dioksin dapat masuk ke dalam tubuh manusia melalui jalan inhalasi (terhirup), ingesti (termakan atau terminum), serta kontak kulit (dermal contact)" (Sumingkrat, 2002).

Terdapat berbagai cara untuk memecah gas dioksin, salah satu cara yaitu pengaturan suhu pembakaran, seperti penelitian yang telah dilakukan oleh Kimberly Febrina "didalam 
insinerator sampah dibakar dengan temperatur tinggi (diatas $850^{\circ} \mathrm{C}$ ) guna memecah gas dioksin akibat pembakaran sampah yang mengandung klor. Untuk menjamin pembakaran berlangsung diatas temperatur $850^{\circ} \mathrm{C}$ insenerator dilengkapi dengan burner (biasanya menggunakan bahan bakar minyak) yang akan menyala apabila temperatur di dalam insinerator kurang dari $850^{\circ} \mathrm{C}$. Insinerator juga dilengkapi dengan blower untuk menyuplai udara sekunder berkecepatan tinggi yang menjamin cukupnya suplai oksigen dan terjadinya mixing yang baik sehingga proses pembakaran menjadi optimal" (Kodrat, 2013).

\section{Teknik Pengelolaan sampah dengan Komposter Anaerob}

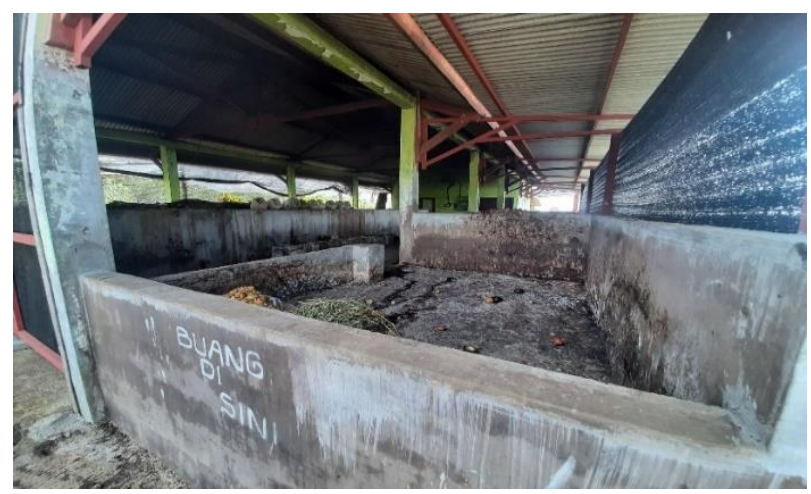

Sumber: Dokumentasi pribadi penulis (2020)

Gambar 3. Tempat Komposter Anaerob.

Komposter Anaerob dibangun dengan tujuan untuk mengurangi kebiasaan buruk petani dalam membuang sampah basah berupa sayuran dan buah. Komposter dibangun dari batu bata, lalu disemen dan pada bagian bawah dilapisi batu koral. Terdapat empat wadah yang dapat digunakan untuk menampung buah dan sayur. Masing-masing ukurannya $3 \times 2$ meter dan tinggi 1,2 meter. Pembuatan komposter menghabiskan dana Rp. 33.000.000 dari BUMDes.

Komposter hanya dikhususkan untuk sampah basah atau organik karena jika dicampur dengan sampah rumah tangga maka tidak akan menjadi belatung dan tidak jadi pupuk. Berbeda lagi ketika dicampur dengan plastik, sehingga lebih lama dalam proses pembusukan yang bisa dijadikan pupuk.

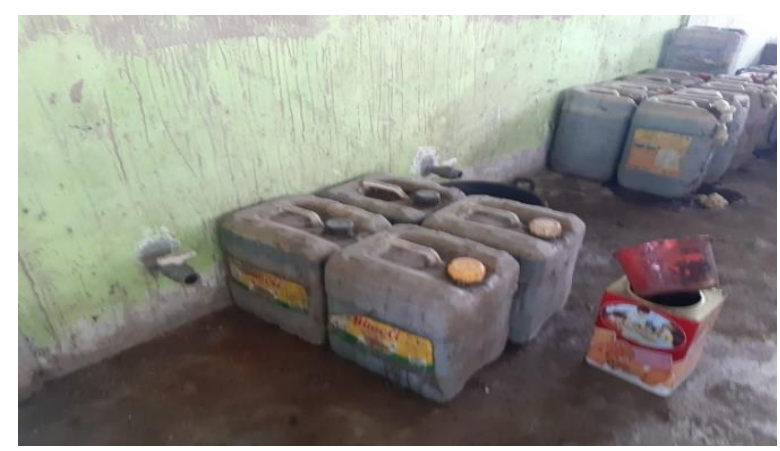

Sumber: Dokumentasi pribadi penulis (2020)

Gambar 4. Hasil Fermentasi Sampah Organik menjadi Pupuk Cair.

Tata cara kerja komposter yaitu: sayuran dan buah-buahan yang busuk dan tidak layak dijual ditaruh kedalam komposter, setelah itu sayuran dan buah-buahan yang ada di dalam komposter dibiarkan selama 8 hari, setelah dibiarkan selama 8 hari, diambil pupuk cairnya dengan ketentuan campuran air 200 mililiter air dan pupuk cair sebanyak 25 liter.

Setelah adanya komposter sampah basah atau organik berupa sisa sayur dan buahbuahan yang dibuang, kemudian bisa diolah menjadi pupuk cair, sehingga dari bentuk sampah yang sebelumnya tidak memiliki nilai guna bisa memiliki nilai guna dan nilai ekonomi.

\section{Bank Sampah}

Teknik Pengelolaan sampah dengan

Bank sampah adalah program nasional dengan fokus kegiatan dalam pengelolaan sampah rumah tangga dengan kategori masih bisa di daur ulang atau dimanfaatkan, dan dikelola secara kolektif oleh masyarakat setempat.

Undang-undang Nomor 18 tahun 2008 "mengamanatkan pengelolaan sampah dengan prinsip 3R (Reduce, Reuse, Recycle). Pemerintah mengajak masyarakat untuk mengurangi, menggunakan kembali dan mendaur ulang sampah, maka pengelolaan sampah dengan pendekatan kumpul-angkutbuang diganti dengan pemilahanpengangkutan-pengolahan-pemrosesan”. 


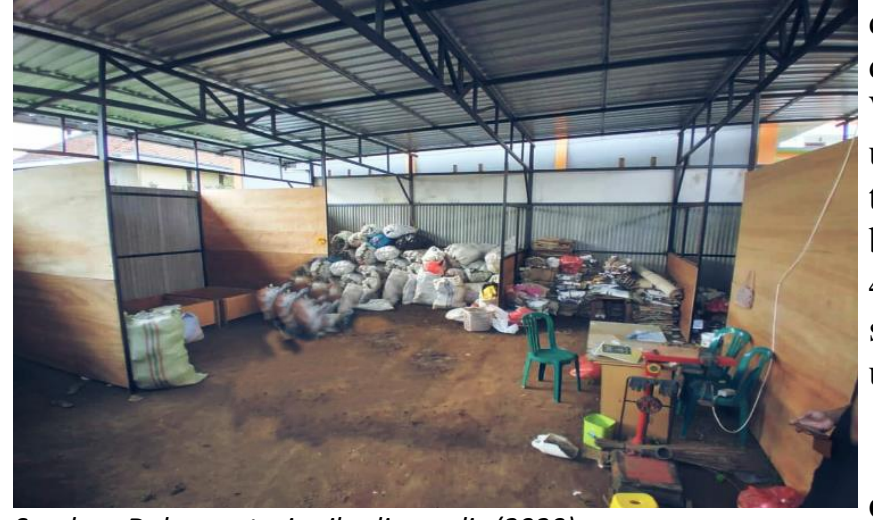

Sumber: Dokumentasi pribadi penulis (2020)

Gambar 4. Bank Sampah BUMDes Rejeki Barokah Desa Sumbergondo.

Bank sampah ini dikelola secara profesional oleh BUMDes Rejeki Barokah. Bank sampah hanya dikhususkan untuk jenis sampah rumah tangga yang masih bisa di daur ulang dan dimanfaatkan. Terdapat beberapa jenis sampah yang dapat dijual, antara lain:

Tabel 1. Jenis barang yang bisa dijual

\begin{tabular}{|c|c|c|c|c|}
\hline No & $\begin{array}{l}\text { Nama } \\
\text { Barang }\end{array}$ & Jenis Barang & Satuan & Harga \\
\hline 1. & Plastik & $\begin{array}{l}\text { Plastik PP } \begin{array}{l}\text { Putih \& } \\
\text { ada }\end{array} \\
\text { Kresek, } \\
\text { PVC Karung, }\end{array}$ & $\mathrm{Kg}$ & $\begin{array}{l}\text { Rp. } 300- \\
\text { Rp. } 1.500\end{array}$ \\
\hline 2. & Bak & $\begin{array}{lr}\begin{array}{l}\text { Bak putih, } \\
\text { campurna, }\end{array} \\
\text { printer, dan } \\
\begin{array}{l}\text { kaca, Aqua geles } \\
\text { dan botol. }\end{array}\end{array}$ & $\mathrm{Kg}$ & $\begin{array}{l}\text { Rp. } 400- \\
\text { Rp. } 3.000\end{array}$ \\
\hline 3. & Kertas & $\begin{array}{l}\text { Kardus, Kertas } \\
\text { semen, HVS, CD, } \\
\text { Koran, Duplek, } \\
\text { Buku }\end{array}$ & $\mathrm{Kg}$ & $\begin{array}{l}\text { Rp. } 400- \\
\text { Rp. } 3.000\end{array}$ \\
\hline 4. & Botol kaca & $\begin{array}{l}\text { Botol bir, Botol } \\
\text { bensin, Coca cola, } \\
\text { drum, kecap, sirup }\end{array}$ & biji & $\begin{array}{l}\text { Rp. } 200- \\
\text { Rp. } 1.000\end{array}$ \\
\hline 5. & Besi & $\begin{array}{l}\text { Besi A \& B, } \\
\text { Omplong, } \\
\text { Rongsok, Kawat }\end{array}$ & $\mathrm{Kg}$ & $\begin{array}{l}\text { Rp. } 400- \\
\text { Rp. } 2.500\end{array}$ \\
\hline 6. & Logam & $\begin{array}{l}\text { Tembaga, } \\
\text { Kunigan, } \\
\text { Alumunium A, B, } \\
\text { C, Acu, Gagang } \\
\text { pintu }\end{array}$ & $\mathrm{Kg}$ & $\begin{array}{l}\text { Rp. } 4.000 \\
-\quad \text { Rp. } \\
40.000\end{array}$ \\
\hline
\end{tabular}

Teknis Pengelolaan melalui Bank Sampah antara lain:

1. Menggunakan pick up atau tosa dari BUMDes, dengan kondisi sampah dalam keadaan kering.

2. Proses penimbangan sampah rumah tangga.

3. Pencatatan hasil yang diperoleh.

4. Pencairan tabungan.

Dengan adanya bank sampah, warga

Desa Sumbergondo bisa memanfaatkan sampah rumah tangga untuk ditabung dan dijadikan uang. Berdasarkaan hasil wawancara dengan salah seorang pekerja di bank sampah, Warsito, melalui sampah ternyata bisa dibuat untuk membayar pajak. Tentu hal tersebut bisa terjadi karena dalam satu tahun, setidaknya bisa menghasilkan uang kurang lebih Rp. 400.000. Selain itu hasil sampah yang di setorkan ke bank sampah dapat dimanfaatkan untuk kegiatan warga.

\section{Bentuk Partisipasi dan Dampak yang dirasakan masyarakat}

Berdasarkan hasil wawancara dengan Direktur BUMDes Rejeki Barokah, Anditya Fitrawan hampir $95 \%$ warga setuju terkait program yang dijalankan. Indikator bisa diterima dan bentuk partisipasi yaitu warga ikut membayar iuran Rp. 10.000 per bulan dan dari iuran tersebut bisa dibuat untuk menggaji karyawan sehingga pengelolaan sampah bisa berjalan dengan baik. Warga setuju karena masalah sampah yang dibakar menggunakan insinerator tidak memberikan pengaruh sama sekali terhadap lingkungan dari pada dibuang ditempat tanpa melewati proses pembakaran karena bau sampah yang ditimbulkan menganggu kenyamanan ketika melewati jalan tersebut.

\section{Dampak yang dirasakan masyarakat}

Secara pasti dampaknya terhadap lingkungan, selama hampir kurun waktu 2 tahun berjalan, mulai tahun 2018 sampai 2020. Lokasi bangunan insinerator dahulunya merupakan titik-titik sampah yang ada di Desa Sumbergondo yaitu di Dusun Tegalsari dan Dusun Sengonan, merupakan tempat warga membuang sampah sepanjang 50-100 meter di pinggir jalan dan sekarang bersih, selain itu :

1. Tidak terjadi penumpukan sampah di sudut wilayah Desa Sumbergondo.

2. Masyarakat dan tamu yang berkunjung ke Desa Sumbergondo tidak lagi mengeluhkan terkait bau sampah yang menyengat.

3. Titik pembuangan sampah sembarangan di Desa Sumbergondo hilang.

4. Dari sisi usaha bisa mengangkat perekonomian warga, dengan pengelolaan sampah, BUMDes bisa mengelola 6 karyawan diantaranya 4 orang untuk pengangkutan sampah dan 2 orang untuk pemilahan sampah atau bank sampah. Gaji pengangkutan sampah Rp. 200.000 per- 
hari dan bukan merupakan pekerjaan harian dan gaji per-bulan Rp. 2.000.000.

5. Sampah bisa dibuat untuk membayar pajak, karena dalam satu tahun, setidaknya bisa menghasilkan uang kurang lebih Rp. 400.000 .

6. Desa bisa lebih dikenal lewat program sampah yang notabenenya sudah didatangi pengunjung dari beberapa daerah di Indonesia diantaranya Papua, Sulawesi, Kalimantan dengan kegiatan studi banding.

\section{PENUTUP}

\section{Kesimpulan}

Peran BUMDes Rejeki Barokah dalam merancang program dan menciptakan alat untuk pengelolaan sampah di Desa Sumbergondo bisa menyelesaikan permasalahan sampah di desa tersebut. Alat insinerator dapat menanggulangi persoalan sampah rumah tangga yang tidak bisa diolah atau didaur ulang dengan cara di bakar.

Walaupun pembakaran sampah menggunakan insinerator yang sudah menggunakan cerobong dan filter pada rangkaian alat insinerator yang dilengkapi alat penyemprot asap hasil pembakaran, untuk mengetahui kualitas udara yang dihasilkan diperlukan pengambilan contoh uji udara emisi cerobong dan menguji kualitas udaranya di laboratorium, sehingga dapat dipastikan asap yang keluar belum boleh disebut aman, karena harus melewati pengujian di laboratorium ada baku mutu udara ambien atau emisi yang harus dipenuhi dan tidak menganggu pernapasan.

Komposter juga memiliki peran dalam mengatasi sampah organik atau basah dengan cara difermentasi dan diambil cairannya yang kemudian bisa dimanfaatkan untuk dijadikan pupuk daun cair. Selain itu bank sampah berperan dalam mengelola sampah rumah tangga sehingga masih bisa diolah kembali dan bernilai ekonomis.

Melalui ketiga sistem pengelolaan sampah yang di kelola oleh BUMDes maka permasalahan sampah di desa bisa teratasi secara mandiri, secara kasat mata lingkungan menjadi lebih bersih, nyaman, tidak ada lagi penumpukan dan titik pembuangan sampah sembarangan. Disamping dapat mengangkat perekonomian warga.

\section{Saran}

Adapun saran dari penelitian ini antara lain:

1. Pada satu sisi pengendalian sampah dari segi jumlah dan estetika (bau) sudah bisa teratasi namun dari segi lingkungan harus ada kajian lebih lanjut yaitu pengukuan kualitas udara pada emisi cerobong, dan saran suhu yang optimal agar pembakaran yang dilakukan sempurna dan asap yang keluar tidak berbahaya. Gas buang dari proses pembakaran berpotensi mencemarkan lingkungan karena kandungan bahan beracun seperti substansi dioksin. Dioksin dapat menimbulkan penyakit berbahaya yaitu kanker.

2. Alangkah baiknya mengunakan insinerator dengan jenis multiple chamber (ruang bakar lebih dari satu), dimana ruang bakar pertama untuk membakar limbah sedangkan ruang bakar kedua untuk membakar gas buang yang dihasilkan pada ruang bakar pertama agar dapat terbakar sempurna.

\section{UCAPAN TERIMA KASIH}

Penulis menyadari bahwa dalam penyelesaian artikel ini tanpa adanya bantuan dan dorongan dari orang lain tidak dapat terwujud, sehingga dengan ketulusan dan kerendahan hati penulis mengucapkan terimakasih dan penghargaan setinggitingginya kepada :

1. Bapak Nuryuwono, selaku Kepala Desa Sumbergondo yang sudah mengizinkan penulis untuk melakukan penelitian.

2. Bapak Anditya Fitrawan, selaku Direktur BUMDes Rejeki Barokah yang telah memberikan ilmu dan sumber data, berupa informasi yang dibutuhkan penulis.

3. Bapak Warsito, selaku pekerja BUMDes yang telah memberikan informasi guna melengkapi data yang sudah diperoleh.

4. Bapak Ali, selaku TU jurusan yang telah membantu mahasiswa dalam memudahkan pelaksanaan penelitian.

\section{DAFTAR PUSTAKA}

Arief, S. (2013). Pengelolaan Sampah Malang Raya Menuju Pengelolaan Sampah Terpadu Yang Berbasis Partisipasi Masyarakat. Jurnal Humanity, 9(1), 195208.

Ariyanto, D. B., \& Wibowo, A. W. (2020). KEBIJAKAN PENGELOLAAN 
SAMPAH DI DAERAH UTAMA TUJUAN WISATA. Kebijakan Publik, 11(2), 105-112.

Dewanti, D. P., Ma'rufatin, A., Oktivia, R., \& Pratama, R. A. (2020). Kebutuhan Karbon Aktif Untuk Pengurangan Dioksin Pada Gas Buang Cerobong Insinerator Pengolahan Sampah Domestik. Jurnal Rekayasa Lingkungan, 13(1), $50-55$. https://doi.org/10.29122/jrl.v13i1.4292

Elamin, M. Z., Ilmi, K. N., Tahrirah, T., Zarnuzi, Y. A., Suci, Y. C., Rahmawati, D. R., ... Nafisa, I. F. (2018). ANALISIS PENGELOLAAN SAMPAH PADA MASYARAKAT DESA DISANAH KECAMATAN SRESEH KABUPATEN SAMPANG. Jurnal Kesehatan Lingkungan, $\quad$ 10(4), 368-375. https://doi.org/10.20473/jkl.v10i4.2018.3 68-375

Kodrat, K. F. (2013). Evaluasi Sistem Pengananan Limbah Padat Klinis dengan Insenerator di RS. H. Adam Malik Medan. Malikussaleh Industrial Engineering Journal, 2(2), 43-49.

Kuncoro, Sejati. 2009. Pengolahan Sampah Terpadu. Yogyakarta: Kanisius.

Mahyudin, R. P. (2017). KAJIAN PERMASALAHAN PENGELOLAAN SAMPAH DAN DAMPAK LINGKUNGAN DI TPA (TEMPAT PEMROSESAN AKHIR). Teknik Lingkungan, 3(1), 66-74.

Purnomo. 2004. Pembangunan Bumdes dan Pemberdayaan Masyarakat Desa. Lombok Timur : Makalah BPMPD.

Putra, A. S. (2015). BADAN USAHA MILIK DESA: SPIRIT USAHA KOLEKTIF $D E S A$. In $B u k u$ 7. Retrieved from http://library1.nida.ac.th/termpaper6/sd/2 554/19755.pdf

Soekanto, Soerjono. 2002. Sosiologi Suatu Pengantar. Jakarta : Rajawali Press.

Soemardjan, Selo. 1986. Perubahan Sosial di Yogyakarta. Yogyakarta: Gadjah Mada University Press.

Sulistiyorini, N. R., Darwis, R. S., \& Gutama, A. S. (2015). Partisipasi Masyarakat Dalam Pengelolaan Sampah Di Lingkungan Margaluyu Kelurahan Cicurug. Share: Social Work Journal, 5(1), 71-80. https://doi.org/10.24198/share.v5i1.13120 Sumingkrat, S. (2002). Terbentuknya Dioksin
Akibat Reaksi Kimia Pada Proses Pembakaran Dan Dampaknya Bagi Manusia. Buletin Penelitian, 24(1), 7-14. https://doi.org/10.24817/jkk.v0i0.4745

Undang-Undang Republik Indonesia Nomor 18 Tahun 2008 tentang Pengelolaan Sampah. 